\title{
Crise econômica e retorno dos emigrantes da microrregião de Governador Valadares
}

\author{
Sueli Siqueira * \\ Mauro Augusto Santos **
}

A questão que norteia este artigo $^{1}$ é a crise econômica e sua influência na consolidação do retorno de um grupo significativo de brasileiros a partir do ano de 2006. Nesse ano, a crise na economia americana atinge o mercado de trabalho secundário, principalmente a construção civil, na qual a maioria dos emigrantes brasileiros está inserida. Esta pesquisa busca compreender os aspectos vivenciados pelos emigrantes no país de destino, destacando as dificuldades enfrentadas com a crise que culminaram em um retorno antecipado.

A Microrregião de Governador Valadares² experimentou nos anos de 1960 um movimento populacional sui generis no Brasil - A emigração internacional. Os primeiros registros de emigrantes para os Estados Unidos oriundos da cidade de Governador Valadares ocorreram em meados da década de 1960. Inicialmente, eram jovens da classe média que com espírito aventureiro buscavam novas perspectivas de trabalho nas terras do tio Sam. Um conjunto de fatores que vão desde a crise na economia brasileira, a existência de um mercado de trabalho atraente no país de destino e a formação de redes sociais, tornavam o projeto de migrar para o exterior acessível para um determinado segmento da população.

\footnotetext{
* Professora do Programa de Pós-Graduação Stricto Sensu em Gestão Integrada do Território da Universidade Vale do Rio Doce - UNIVALE. Doutora em Sociologia e Politica.

** Professor do Programa de Pós-Graduação Stricto Sensu em Gestão Integrada do Território da Universidade Vale do Rio Doce - UNIVALE. Doutor em Demografia.
} 
Na segunda metade dos anos de 1980, esse movimento toma proporções maiores irradiando-se por toda a Microrregião, configurando os locais de origem e destino (SIQUEIRA, 2008).

$O$ projeto de emigrar passa pelo desejo de ir, fazer poupança, adquirir bens na cidade de origem e retornar em situação socioeconômica mais elevada. Vale lembrar que a forma como é definida a direção do fluxo migratório tem fortes componentes sociais, culturais e históricos (SIQUEIRA, 2009).

A idealização de "conquistar a América" ${ }^{3}$ é comum na perspectiva do emigrante que busca "ganhar dinheiro". Destaca-se também que, no país de destino, o emigrante trabalha arduamente com objetivo de acumular dinheiro para adquirir bens no país de origem e retornar, de acordo com o planejado. Entretanto, ocorrem eventos não esperados que determinam o retorno antecipado.

A crise econômica estabelecida nos Estados Unidos em meados de 2006 marca o início de um novo fluxo dentro do fenômeno migratório brasileiro: o dos retornados sem cumprir as metas planejadas. Este estudo tem como objetivos: traçar o perfil socioeconômico desse emigrante; indicar os motivos da emigração; descrever a vida social e a atividade profissional no Brasil antes de emigrar e nos Estados Unidos; destacar a visão do emigrante em relação ao Brasil e ao país de destino; indicar os motivos do retorno; destacar as expectativas do emigrante em relação a sua renda no Brasil; descrever os projetos do emigrante ao retornar; avaliar os efeitos psicológicos do retorno para o emigrante e seus familiares.

$\mathrm{O}$ artigo se baseia nos dados da pesquisa realizada na Microrregião de Governador Valadares com emigrantes, maiores de 18 anos, retornados dos Estados Unidos no período de 2006 a 2010. Estes sujeitos foram localizados através da técnica bola de neve, ou seja, após a indicação dos primeiros, esses indicaram outros, que por sua vez, também fizeram outras indicações, até chegar a um número em que as informações e indicações começaram a se repetir. Foram realizadas 237 entrevistas formais nos 25 municípios que compõem a Microrregião. Foram também realizados cinco grupos focais nos seguintes municípios: Governador Valadares, Galileia, Capitão Andrade, Sobrália e Itambacuri. Os participantes dos grupos focais foram selecionados, aleatoriamente, dentre aqueles que aceitaram participar da pesquisa. 0 grupo focal apresentou a seguinte constituição: $50 \%$ homens e $50 \%$ mulheres, solteiros e casados, retornados que se encontravam em situação regular e irregular, indivíduos que permaneceram nos Estados Unidos por pelo menos três anos. Cada grupo teve, no mínimo, oito participantes que atendiam de modo igualitário às características definidas. Com base nos dados coletados através desta metodologia, buscamos compreender as condições de retorno dos emigrantes, a realização ou não do projeto que motivou a emigração e sua reinserção no mercado de trabalho no país de origem ${ }^{4}$. 


\section{A emigração na microrregião de Governador Valadares}

A cidade de Governador Valadares, em Minas Gerais, é a cidade de onde se origina o primeiro ponto de emigração, em maior escala, de brasileiros para o exterior. Na década de 1960 , os primeiros trabalhadores valadarenses empreenderam a migração de longa distância, em busca do mercado de trabalho secundário nos Estados Unidos. Ao longo das décadas seguintes, outros seguiram o mesmo percurso, formando uma rede que, na segunda metade dos anos de 1980, se consolida e torna-se um dos maiores fluxos emigratórios de brasileiros para o exterior. Posteriormente, outros municípios passaram a fazer parte desse fluxo e outros países, como Portugal, Itália, Espanha e Inglaterra passaram a também figurar como destino dos brasileiros que emigram.

De acordo com os dados do Censo Demográfico de 2010, entre os dez municípios brasileiros com maior número de emigrantes internacionais, Governador Valadares, com uma população de 263.689 habitantes e um total de 8.800 emigrantes no exterior, ocupa a sétima posição. Os municípios de São Paulo, Rio de Janeiro, Belo Horizonte, Goiânia, Curitiba e Salvador, nesta ordem, tiveram um volume de emigrantes maior que o de Governador Valadares. Com menor volume, também ordenados, temos: Brasília, Porto Alegre e Fortaleza. Para se avaliar o impacto da emigração em Governador Valadares, basta ressaltar que este é o município de menor população entre os dez que foram listados. Goiânia, que, depois de Governador Valadares, é o menor município, ainda assim possui uma população cinco vezes maior que a do município mineiro.

Sobre o perfil do emigrante valadarense no exterior, os dados do último censo demográfico mostram que o percentual de homens (58\%) era consideravelmente maior que o de mulheres (42\%). Os jovens com idade entre 20 e 29 anos totalizavam $29 \%$ desses emigrantes. Já os emigrantes com idade entre 30 e 39 anos totalizavam $31 \%$ e os com idade entre 40 e $49,26 \%$. A maioria estava residindo nos Estados Unidos (66\%) ou em Portugal (23\%) e teve a última partida para o exterior acontecendo entre os anos de 2005 e 2010 (50\%) - outros $33 \%$ deixaram o Brasil entre os anos de 2000 e 2004 e 12\% entre 1990 e 1999.

Outro dado do Censo Demográfico de 2010 a ser ressaltado, é o de que todos os dez municípios com maior proporção de emigrantes internacionais considerando o número de imigrantes por grupo de mil habitantes - se localizam nas proximidades de Governador Valadares.

\section{A crise e o retorno}

As décadas transcorridas desde o início da emigração marcaram a história dos municípios da Microrregião de Governador Valadares e seus habitantes. A emigração passou a fazer parte do cotidiano da região. Emigrar, ganhar dinheiro e retornar passou a ser um projeto de vida acessível e desejado por muitos.

O boom do fluxo emigratório da Microrregião de Governador Valadares 
aconteceu na segunda metade dos anos de 1980, coincidindo com o período em que também se intensifica a crise econômica brasileira. Os habitantes dessa região, devido às redes sociais estabelecidas nas duas décadas anteriores, veem como uma possibilidade de fugir da crise a emigração para os EUA. Ao longo dos anos seguintes muitos emigram e retornam, contudo, em meados de 2006 observa-se um retorno mais acentuado. São os fugitivos da forte crise econômica que, desta vez, atingia o país escolhido como destino desses emigrantes.

A crise, que segundo Brussee (2005) teve início na década de 1990, foi provocada pela falta de controle do mercado financeiro americano que atraiu uma grande quantidade de investidores com a promessa de ganhar dinheiro fácil. Entretanto, esses investidores compraram títulos sem a percepção do grande risco associado aos mesmos, pois adquiriram títulos subprime.

Subprime são os consumidores que possuem um perfil que não garante crédito nas instituições financeiras, pois não têm renda comprovada, emprego fixo e histórico positivo de crédito. Com a economia em crescimento, estes consumidores possuem renda, geralmente adquirida no mercado informal. Percebendo a existência desse mercado consumidor, as instituições financeiras lançaram títulos com base no poder de compra desses consumidores. Quando o mercado de trabalho secundário foi atingido pela crise, os trabalhadores perderam o poder de compra e, consequentemente, não conseguiram efetuar os pagamentos de suas dívidas (CARVALHO, 2008).

Inicialmente instalada no setor imobiliário, a crise agravou-se quando a falta de confiança nos papéis financeiros atingiu o mercado de capitais como um todo. A maioria das instituições financeiras que adquiriu hipotecas subprime, neste momento da crise, entrou em insolvência ou falência, atingindo todos os setores da economia americana.

A crise no setor imobiliário atingiu diretamente grande parte dos emigrantes que trabalhavam na construção civil e também aqueles que, encantados pelo crédito fácil, resolveram investir suas economias na aquisição de imóveis naquele país.

A crise provocou a redução das horas de trabalho, a queda do valor pago e, consequentemente, a redução dos ganhos e o aumento do custo de vida. Para muitos não houve como permanecer nos Estados Unidos, e o retorno passou a ser a única alternativa. Quem são esses indivíduos que retornam neste contexto? Quais são os impactos desse retorno para o sujeito e o local de origem? As respostas para estas questões é o que buscaremos na análise proposta nas seções seguintes.

\section{Análise dos resultados}

\section{Perfil dos entrevistados}

Os emigrantes retornados são, em sua maioria, homens (73\%). A predominância de homens chama atenção pelo fato de que estudos destacam, 
desde o final dos anos de 1990, a igualdade de gênero nos fluxos migratórios (ASSIS, 2007; FUSCO, 1998). O percentual elevado de homens nessa pesquisa é um indicativo de que os homens, em função da crise, retornam com mais intensidade que as mulheres. Tal fato pode ser explicado pelo impacto da crise na construção civil, nas atividades de jardinagem e nas associadas a bares e restaurantes, nichos de trabalho que normalmente são ocupados por indivíduos do sexo masculino. As atividades de faxina, babá e cuidadora de idosos, que têm uma presença maior de mulheres, também sofreram o impacto da crise, mas em menor intensidade.

Considerando o total de casos $(n=237)$, temos que a maioria dos entrevistados emigrou quando tinha uma idade entre 21 e 30 anos (41\%). Os que emigraram com idade entre 18 e 20 anos totalizaram $31 \%$ da amostra ${ }^{5}$. Com relação à escolaridade, $36 \%$ possuíam o ensino fundamental completo, $37 \%$ o ensino médio completo e $5 \%$ formação superior. Destaca-se, ainda, que 17,3\% emigraram na década de 1990 e 34\% no início dos anos 2000.

Confirmando dados de pesquisas realizadas na região (SALES, 1999; ASSIS, 2011; SIQUEIRA, 2008), a maioria dos emigrantes (51\%) entrou de forma irregular nos Estados Unidos pela fronteira (México ou Canadá) ${ }^{6}$. Os que entraram no país usando documentos falsos totalizaram $10 \%$ da amostra. Outros entraram com visto de turista (28\%) ou com documento de cidadania italiana (8\%). Neste sentido é importante destacar que, ao entrar para o mercado de trabalho, os portadores de visto de turista e cidadania italiana, tornam-se também irregulares. Para buscar o visto de turista existem agências de turismo que organizam a documentação, informam como proceder na hora da entrevista, como se vestir, fazem o agendamento e oferecem transporte terrestre até o consulado. Estes são mecanismos facilitadores que tornam a emigração acessível para os moradores da região (SIQUEIRA, 2009). Os resultados da pesquisa também revelaram que a maioria dos emigrantes entrevistados (89\%) retornou ao Brasil na mesma situação em que se encontravam quando chegaram aos Estados Unidos, ou seja, continuavam em situação irregular.

A longa história dos fluxos migratórios na região propiciou o surgimento de outros mecanismos facilitadores para concretização do projeto migratório por meios ilícitos. $\mathrm{O}$ agenciador, conhecido como "cônsul", organiza a viagem para os Estados Unidos via fronteira. Através de um simples telefonema é possível entrar em contato com esses indivíduos que organizam toda a viagem por um custo entre nove a treze mil dólares (SIQUEIRA, 2009). Neste sentido, é interessante ressaltar que $45 \%$ dos entrevistados fizeram empréstimos com amigos e parentes para custear o projeto migratório e $26 \%$ utilizaram recursos próprios.

Do total de entrevistados, a maioria estava inserida no mercado de trabalho quando emigrou, sendo que $39 \%$ recebiam até dois salários mínimos ao mês e $26 \%$ acima de dois até cinco salários mínimos. Pesquisas anteriores confirmam estes dados (SALES, 1999, ASSIS, 2011), pois as mesmas demonstram que o perfil dominante entre os emigrantes brasileiros nos Estados Unidos é composto por 
jovens que estavam inseridos no mercado de trabalho na época da emigração. A emigração é uma alternativa viável para os moradores da região aumentarem sua renda e adquirirem bens duráveis. Os mecanismos facilitadores disponibilizados ${ }^{7}$ na origem possibilitam a um jovem com pouca ou nenhuma experiência de viagem internacional empreender um projeto de emigração de longa distância. As redes sociais, construídas desde a década de 1960, dão suporte ao projeto e ao deslocamento (SIQUEIRA, 2009; FUSCO, 1998).

É interessante destacar que $42 \%$ dos entrevistados informaram possuir bens antes de emigrar. Dentre esses, $22 \%$ possuíam casa, $13 \%$ automóvel, $13 \%$ moto, $3 \%$ fazenda e $4 \%$ possuíam algum tipo de comércio. Estes dados nos permitem reforçar o que outros estudiosos do fenômeno já afirmaram, ou seja, os emigrantes contemporâneos se distinguem dos primeiros emigrantes do início do século XX exatamente por estas características. Eles não são totalmente desprovidos de bens e emigram em busca, principalmente, de ampliar a renda e de adquirirem bens duráveis (ASSIS, 1995). Eles possuem informações que circulam nas redes sociais e capital humano para processar a mobilidade de longa distância (HALL, 2003).

Segundo o Princípio da Causalidade Cumulativa de Myrdal (1957), alguns processos/mudanças sociais, ao ocorrerem, em vez de provocarem a ação de forças contrárias que atuariam no sentido de restaurar a situação de equilíbrio existente antes do desencadeamento do processo, provocariam novas mudanças que fariam com que o sistema se movimentasse na mesma direção para a qual foi impelido pela mudança inicial. O resultado disso é que, devido a esta causalidade circular, os processos sociais tenderiam a se tornar cumulativos, aumentando gradativamente a sua força. A partir do princípio proposto por Myrdal, vários cientistas sociais têm apontado alguns fatores que explicariam o fato da migração se perpetuar através do tempo, sendo que o papel das redes sociais é um dos mais citados.

Vários autores têm destacado o papel das redes sociais sobre a perpetuação dos movimentos migratórios (HARBISON, 1981; MASSEY, 1990; MASSEY et al., 1987; MASSEY et al., 1993; TAYLOR, 1986; FAWCETT,1989; SANTOS et al., 2010). Segundo Massey et al. (1993, p. 448), a existência de redes migratórias de trabalho aumenta a probabilidade de sucesso do movimento internacional, pois estas redes "reduzem os custos e riscos do movimento e aumentam a expectativa de retorno com a migração. As redes migratórias constituiriam uma forma de capital social que propiciaria às pessoas terem acesso ao mercado de trabalho no exterior". A migração se tornaria um processo que se autoperpetuaria a partir do momento em que a rede de contatos entre duas regiões atingisse um ponto crítico. A partir de então, o volume dos fluxos migratórios entre essas duas regiões não estaria fortemente relacionado a diferenças salariais ou de níveis de emprego, mas, sim, ao crescimento das redes sociais de migrantes. 0 crescimento das redes teria como efeito a redução gradativa dos custos e dos riscos associados aos movimentos migratórios até atingirem um ponto em que esses movimentos tornam-se independentes dos fatores que os originaram. 
Os dados da pesquisa comprovam o papel fundamental das redes sociais, uma vez que todos os entrevistados possuíam pelo menos um parente ou amigo no local de destino e $75 \%$ possuíam um parente próximo à cidade para a qual emigrou - tais como primos (43\%), tios (18\%) e irmãos (10\%). As redes sociais unem origem e destino, possibilitando, como já ressaltado acima, a redução dos riscos e constrangimentos. Ter alguém que busque no aeroporto, hospede, indique trabalho e dê as informações necessárias para transitar numa sociedade, da qual em muitos casos não se conhece sequer o idioma, é algo fundamental.

Eu não tinha ideia de onde eu tava, era um mundo [aeroporto de New York], acho que maior que essa cidade [...] tudo muito diferente [...] fiquei meio tonto..., meio bobo [...] quando vi meu primo foi o maior alívio. Se não fosse eles [os amigos e parentes] que me ensinaram tudo, eu não sobrevivia um dia [...] é muito diferente, você não tem ideia [...] (Mauro, 39 anos, Gov. Valadares).

[...] eu fui porque tinha meu irmão lá. Ele arranjou o dinheiro e deu todas as dicas [...] fiquei na casa dele até conseguir meu lugar [...] a gente chega sem saber de nada, parece uma criança boba, eles é que ajudam a gente [...] (Marina, 32 anos, Galileia).

\section{Motivos da emigração e do retorno}

O projeto de emigrar passa sempre pelo desejo de fazer poupança e retornar em condições econômicas melhores (SIQUEIRA, 2009). Os dados da pesquisa demonstram exatamente este desejo, pois a principal motivação destacada pelos entrevistados é a possibilidade de ganhar dinheiro (61\%) e melhorar de vida (23\%) no retorno para sua cidade de origem.

A crise na economia americana atingiu o setor imobiliário provocando uma redução drástica na demanda por mão de obra neste setor e atingindo diretamente os emigrantes que viram seus empregos sumirem (SILVA et al., 2010; TORRES FILHO, 2008). A queda do valor do dólar em relação ao real reduziu ainda mais as vantagens econômicas da emigração.

Como principal motivo para o retorno (gráfico 1), foram citados: saudades da família (32\%) e aspectos relacionados à crise econômica (30\%), como a queda no valor da hora de trabalho e a dificuldade de conseguir trabalho. Segundo Piore (1979) a demanda por trabalhadores desqualificados no mercado de trabalho no país de destino é uma variável importante para explicar as migrações internacionais. Este mercado de trabalho é considerado pelos trabalhadores nativos de pouco prestígio e de baixa remuneração, contudo, para os emigrantes é atrativo. A atração está, exatamente, na expectativa de trabalhar muito, ganhar dinheiro em pouco tempo, fazer uma poupança e retornar em condições 
econômicas melhores. Quando esse atrativo deixa de existir, muitos optam por retornar, mesmo antes de concretizarem seus objetivos. No relato abaixo fica evidente este aspecto que motiva o retorno.

[...] vi que não dava mais, trabalhava todos os dias [...] tinha vez que nem folga tinha [...] depois ficava até quatro dias sem trabalhar [...] quando começou a não dá nem pra mandar dinheiro eu vi que tava na hora de vim [...] (Jorge, 45 anos, Capitão Andrade).

\section{Gráfico 1 - Principais motivos para o retorno ao Brasil}

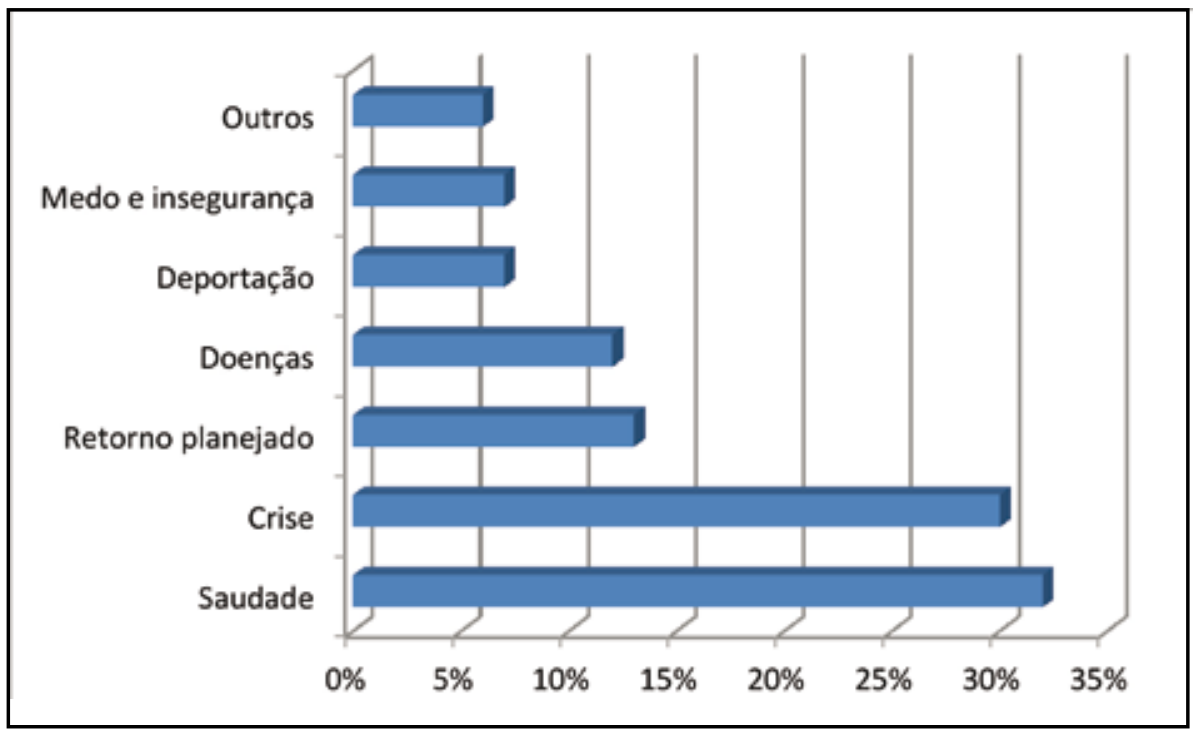

Fonte: Pesquisa de campo, 2011. A questão admitia respostas múltiplas ( $n=237)$

O gráfico 1 mostra também, como motivo de retorno, o fato de já ter alcançado o objetivo econômico do projeto migratório (13\%). No relato abaixo temos uma situação que retrata esse fato. Provavelmente, se as condições de ganhos continuassem positivas, esse emigrante, mesmo já tendo alcançado seu objetivo econômico, e levando em consideração a insistência da família para o seu retorno, ficaria por mais algum tempo.

Eu já tinha feito alguma coisinha aqui e lá tava ruim demais [...] a mulher tava sempre falando pra vim [...]. Não valia mais a pena o sofrimento [...] (Bento, 32 anos, Sobrália).

Como já ressaltado anteriormente, o projeto de emigrar compõe-se basicamente de três estágios: ir, ganhar dinheiro e retornar ao país de origem com 
condições melhores de vida (SIQUEIRA, 2009). Sendo assim, observou-se através da presente pesquisa, que a variável ganhar dinheiro foi o principal motivo de emigrar, enquanto a queda nos ganhos representa o principal motivo de retorno.

É interessante destacar que o retorno é constitutivo do projeto de emigrar. Contudo, a partir de 2006, com a crise instalada na economia americana e a desvalorização do dólar, as razões para o retorno mudam. Anteriormente, o retorno se dava, na maioria dos casos, depois de se ter alcançado sucesso no projeto, ou seja, após obter uma melhora na qualidade de vida no local de origem do emigrante. Após a crise, conforme apresentado no gráfico 1 , o retorno se dá mais em função do custo benefício da emigração não ser mais positivo.

Ainda no gráfico 1 , vale ressaltar dois outros motivos apresentados pelos entrevistados: a deportação (7\%) e o medo e insegurança devido ao aumento da fiscalização da Imigração (7\%). Com o atentado às Torres Gêmeas, em New York em 2001, a Imigração acirrou a fiscalização. As exigências para obter a carteira de motorista, documento indispensável para o trabalhador se locomover, ficaram maiores. Além disso, as blitze aumentaram e a conexão da fiscalização rodoviária, em alguns estados americanos, com a polícia de Imigração, tornou possível identificar os motoristas que tivessem algum processo na justiça, identificando os emigrantes irregulares. Por tudo isso, o cotidiano do emigrante irregular tornouse mais inseguro e o medo da deportação se fez presente mais efetivamente.

[...] fui deportado, pego numa blitz [...] não tinha isso não [...], foi depois do atentado que ficou assim [...]. Fiquei mais de um mês preso [...] (Eduardo, 27 anos, Grupo focal Itambacuri).

\section{Trabalho, projetos e expectativas}

Do total de entrevistados, $81 \%$ trabalhavam antes de emigrar. Os dados do gráfico 2 demonstram que 30\% desses eram comerciários, 18\% prestadores de serviços e $18 \%$ trabalhadores rurais. A renda da maioria desses trabalhadores era de até dois salários mínimos mensais (53\%). Com essa renda, a realização de seus projetos de aquisição da casa própria e o acesso a determinados bens de consumo seria inviável no curto prazo. A emigração seria o meio mais rápido e acessível para os moradores da região realizar seus projetos de consumo.

É interessante destacar, entre os entrevistados, o relativamente alto percentual de trabalhadores rurais (18\%). Segundo estudos de Siqueira (2009), a emigração internacional da população rural, principalmente dos moradores dos pequenos municípios da Microrregião de Governador Valadares, que residem nas áreas urbanas, mas exercem suas atividades nas áreas rurais, se intensificou no final dos anos de 1990. São pequenos produtore rurais, meeiros ou lavradores que, se utilizando dos mecanismos facilitadores de crédito, conseguem financiamento e emigram pela via irregular. 


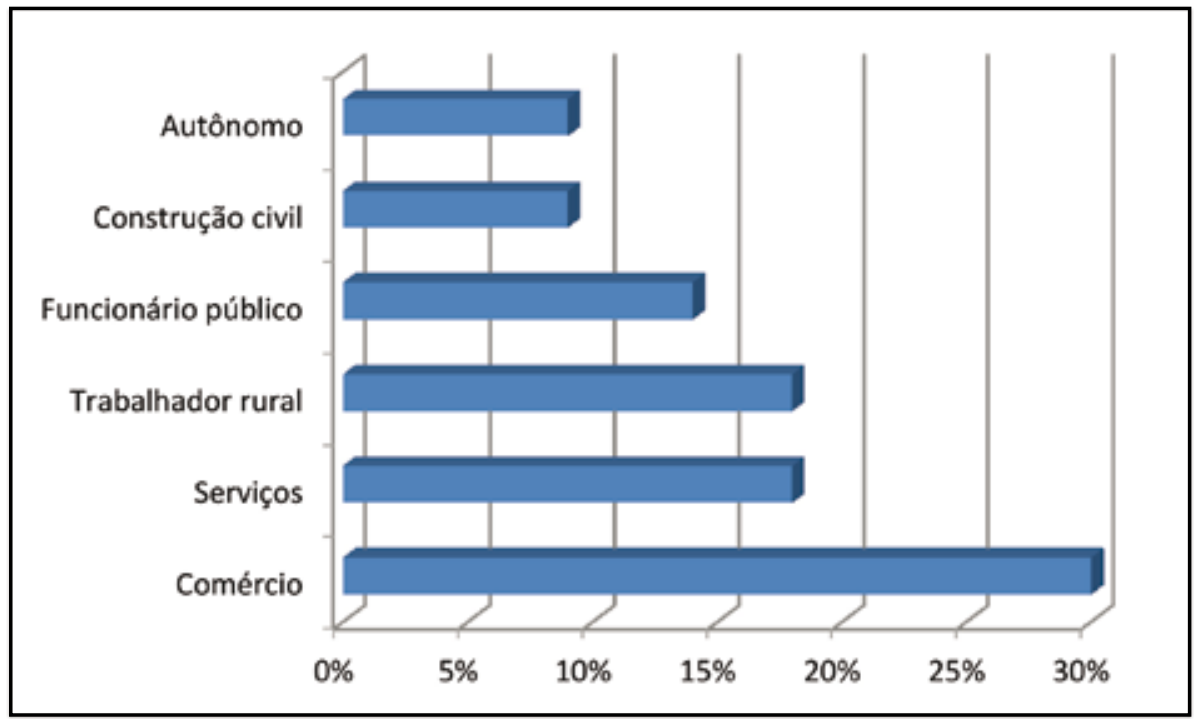

Fonte: Pesquisa de campo, 2011 ( $n=192)$.

Existe, na região, o imaginário coletivo de que os Estados Unidos são um país de oportunidades onde o acesso ao consumo e a bens duráveis é facilitado. Ao longo dos anos, a visibilidade do sucesso daqueles que retornavam e construíam suas casas, mobiliavam com móveis e eletrodomésticos de última geração, além de adquirirem carro e iniciarem um negócio, instigou cada vez mais o desejo de emigrar daqueles que permaneciam (SIQUEIRA, 2010).

Aqueles emigrantes que conseguiram fazer investimentos na cidade de origem, constroem casas grandes e coloridas, que se destacam das casas da rua onde moram. Essa é uma marca visível das possibilidades da emigração. Os aspectos negativos, como a dor da ausência, a solidão, o trabalho pesado e estafante que rouba a saúde e o medo de viver clandestinamente em um país estrangeiro, não são visíveis. Essa visibilidade foi fator que estimulou a emigração ao longo das últimas cinco décadas.

O que foi dito anteriormente pode ser relacionado ao conceito de privação relativa, elaborado pelos Novos Economistas da Migração do Trabalho (STARK \& BLOOM, 1985; STARK \& TAYLOR, 1989; STARK \& TAYLOR, 1991; TAYLOR, 1986). Para estes teóricos, o efeito provocado pelo aumento da renda domiciliar irá depender do contexto socioeconômico em que está inserido o domicílio. Seus moradores avaliariam sua situação de privação, tendo como parâmetro certo padrão de distribuição de renda. Quanto maior o número de domicílios com renda superior, maior será o sentimento de privação relativa. Desta forma, a migração representaria uma possibilidade de melhorar a posição relativa do domicílio, 
dentro do seu grupo de referência. Entretanto, haveria o risco de que o indivíduo que emigrou venha a substituir o seu grupo de referência por um grupo do local de destino, o que levaria o domicílio a não reduzir o seu sentimento de privação relativa ou, até mesmo, aumentá-lo (STARK \& TAYLOR, 1989). Analisando a relação entre o sentimento de privação relativa e a probabilidade de migrar, Stark \& Taylor (1989) concluem que os moradores de um domicílio tenderão a enviar seus membros para locais onde o retorno potencial do movimento migratório seja grande - ou que possibilitem alterar a posição relativa do domicílio na escala de distribuição de renda - e onde o risco de substituição do grupo de referência seja o menor possível.

Ao chegar aos Estados Unidos, os emigrantes se inserem no mercado de trabalho secundário, trabalhando principalmente na construção civil (40\%), na faxina (28\%), em restaurantes (21\%) e em atividades ligadas a jardinagem (gráfico 3). Em média, trabalham 12 horas por dia durante seis dias da semana.

[...] lá a gente só pensa em trabalhar, esquece da vida [...] tudo pra ganhar mais verdinha. Parece que a gente fica meio doido [...]. Eu trabalhava mais de 12 horas todo dia [...] tinha vez que fazia isso semana atrás de semana, sem parar um dia [...] coisa de louco (Ana, 31 anos, Governador Valadares).

\section{Gráfico 3 - Principal atividade nos Estados Unidos}

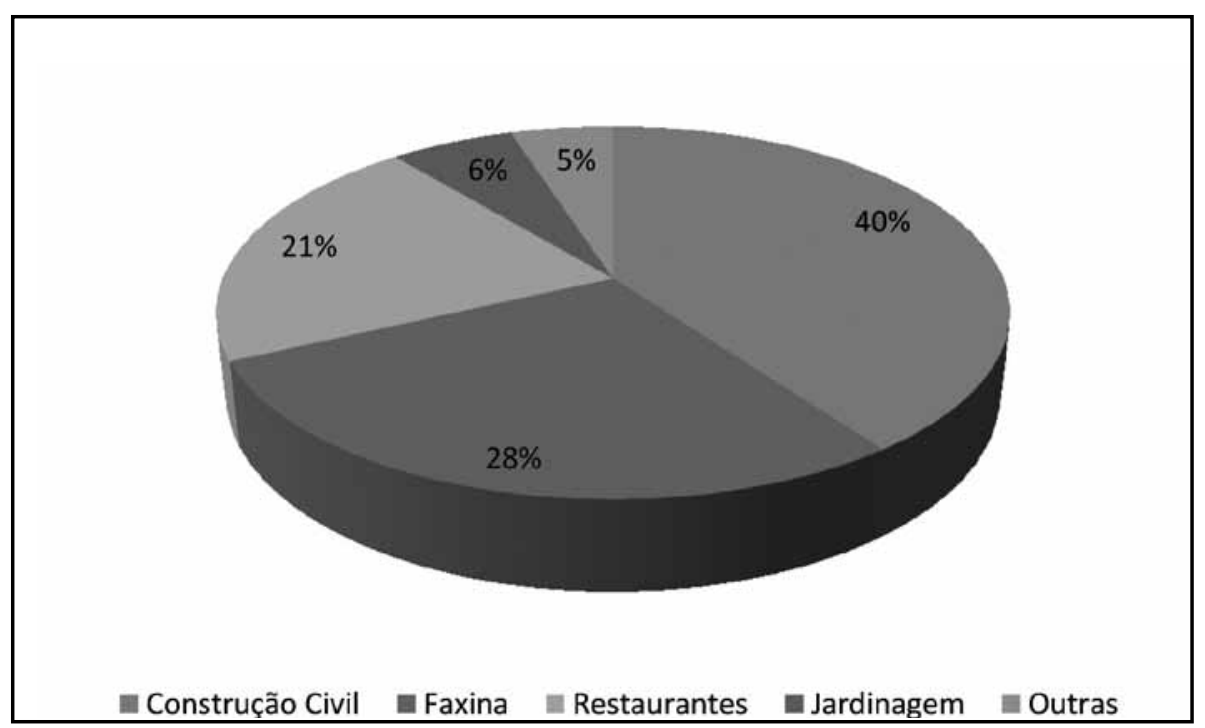

Fonte: Pesquisa de campo, $2011(n=237)$.

Nos Estados Unidos, a maioria (68\%) tem uma renda entre 501 e 1.000 dólares semanais. Esta é uma renda que, quando remetida para o Brasil, possibilita 
adquirir os bens sonhados. Alguns chegam a ganhar até dois mil dólares por semana, mas para isso precisam trabalhar em dois ou mais empregos, chegando a trabalhar mais de 15 horas por dia.

Tinha dia que chegava em casa e tinha que pensar o que ia fazer [...] comer, tomar banho ou dormir [...] não dava tempo para fazer as três coisas (Rubens, 30 anos, Galileia).

Os projetos giram em torno do desejo de adquirir bens que possibilitem uma melhora na sua posição social na origem. Do total de entrevistados, a maioria (78\%) não alcançou esse objetivo, pois enfrentaram a situação de crise na economia americana e retornaram sem adquirir os bens sonhados e mudar sua posição social no município de origem. Dentre os $22 \%$ que fizeram investimento no retorno, 55\% compraram ou reformaram a casa onde residiam, $17 \%$ compraram terras e $15 \%$ montaram algum tipo de comércio.

Nas discussões dos grupos focais ficou evidente a decepção dos participantes em relação ao projeto migratório. $O$ fato da maioria não ter conseguido adquirir nenhum bem no retorno deixa a sensação de tempo perdido, conforme pode ser verificado no depoimento a seguir:

A gente volta sem chão, sem lugar [...] perde tudo [...]. Fica mais difícil, voltei pior do que fui [...] (Margarida, 41 anos, Sobrália).

Ganhei dinheiro sim, comprei casa... vivia bem, mas depois foi só perder. Trabalho sumiu e os dólares também, fica até uma semana sem trabalhar [...] perdi a casa e tudo. [...] agora é começar de novo [...] é difícil, muito difícil [...] (Ilzete, 48 anos, Itambacuri).

\section{Qualidade de vida no Brasil e nos Estados Unidos}

É interessante observar que, na entrevista formal, $50 \%$ dos entrevistados consideraram a vida nos Estados Unidos como sendo boa e outros $30 \%$ a consideraram ótima. Apenas $2 \%$ consideraram a qualidade de vida nos EUA péssima. Estes dados revelam que, apesar de declarem que trabalham muitas horas, têm pouco lazer e sentem muitas saudades do Brasil, o saldo da experiência migratória é percebido como positivo.

Destaca-se, também, a avaliação que fazem da vida no Brasil depois do retorno. Para $42 \%$, houve uma melhora no padrão de vida e outros $22 \%$ consideram que possuem, atualmente, um bom padrão de vida.

Os entrevistados declararam ter poucas atividades de lazer nos Estados Unidos. As atividades mais citadas foram assistir TV e passear nos parques. Contudo, estas atividades são realizadas esporadicamente, como afirmam $35 \%$ dos entrevistados. Diferentemente, quando se referem ao lazer no Brasil, eles 
destacaram que, antes de emigrar, praticavam esportes, visitavam amigos e frequentavam clubes.

\section{Vivendo a crise nos Estados Unidos}

Nunca pensei que num país como aquele podia acontecer isso, achava que era só no Brasil. [...] quando falavam de crise, eu dizia que era coisa de jornal, de gente que queria ver o circo pegar fogo [...] só acreditei quando doeu no meu bolso e eu não consegui pagar minhas contas; a verdade caiu na minha cabeça quando perdi minha casa (Camilo, 42 anos - Governador Valadares).

O depoimento acima representa bem a trajetória de muitos brasileiros. Independente da condição de ser documentados ou não, a publicidade voltada para a aquisição da casa própria, a disponibilidade de uso do cartão de crédito foram tentadoras. Os emigrantes eram classificados como subprime e tinham um perfil de crédito de alto risco, pois, não tinham como comprovar renda. Entretanto, esses mesmos indivíduos possuíam renda suficiente para consumir bens e serviços disponíveis no mercado. Este segmento do mercado atraiu o setor imobiliário que passou a oferecer crédito para o mesmo.

Camilo e sua esposa eram típicos subprime. Não tinham emprego fixo ou um histórico de crédito positivo, mas tinham renda suficiente para consumir. Atendendo aos constantes anúncios de venda de imóveis, compraram uma casa de duzentos e vinte mil dólares em 2002. A prestação cabia no orçamento, pois ele e a esposa ganhavam mais de quatro mil dólares por mês, trabalhando na construção civil e na faxina, respectivamente. O projeto inicial de retornar foi mudado e a família definiu os Estados Unidos como seu local de residência definitiva. Ampliaram o consumo e deixaram de poupar, usando todo o limite de compras do cartão de crédito. Em 2007, a prestação da casa aumentou e, ao mesmo tempo, a oferta de trabalho e o valor da hora de trabalho caíram, tanto para ele como para a esposa. Não conseguiam pagar a fatura do cartão de crédito e a prestação da casa. Em menos de um ano perderam a casa e avaliaram que já não valia a pena viver nos Estados Unidos. Resolveram, então, retornar para o Brasil.

A ideia que perpassa o imaginário popular dos moradores da Microrregião de Governador Valadares, de que os Estados Unidos seriam um país rico e poderoso onde seria possível ganhar muito dinheiro, desmoronou para muitos que, como Camilo, voltaram para sua terra natal. A redução da oferta de trabalho, a queda do valor da hora de trabalho e a desvalorização do dólar foram fatores concretos que demonstraram para muitos emigrantes que o "custo-benefício" de permanecer nos EUA já não era positivo e o retorno seria uma opção. 
Alguns emigrantes permaneceram nos Estados Unidos, mas o projeto mudou, pois já não é possível ganhar muito dinheiro, poupar e investir no Brasil, ou mesmo investir no destino. Como no relato abaixo, o salário já não permite poupar, só manter as despesas.

“[...] lá agora é assim, trabalho pouco e ganho difícil. Viver lá é igual aqui, trabalhar para comer. Pra viver assim, vivo aqui, é melhor" (Ana, Governador Valadares).

\section{Expectativas e projetos no retorno}

Projeto de renda no Brasil

Apenas $13 \%$ dos entrevistados planejaram o retorno para o Brasil. Para a grande maioria o retorno foi traumático, pois além de não ter sido planejado, significou, para muitos, o fim do sonho de conseguir melhorar o seu padrão de vida no seu município de origem, além do constrangimento de retornar em situação pior da que se encontravam quando emigraram.

Após o retorno, nessas condições, conseguir obter renda e manter o padrão de vida é a meta de todos. Entretanto, a incerteza e a insegurança estão presentes no cotidiano desses cidadãos. Isso fica evidente nos relatos.

[...] tenho um dinheiro para iniciar alguma coisa, mas não sei por onde começar ... é tudo muito difícil ... fico com medo de perder o pouco que trouxe (Grupo focal Galileia, participante 4).

Tenho os aluguéis que vai dar pra começar, mas vou ter que dar um jeito, a gente está acostumado com uma vida diferente ... não sei não... vou procurar emprego, mas acho que está difícil pra mim [...](Grupo focal Governador Valadares, participante 1).

No gráfico 4 é possível ver que $59 \%$ dos entrevistados já possuem investimentos que possibilitam auferir alguma renda, outros $12 \%$ possuem emprego e $8 \%$ possuem capital para investir. Contudo, $11 \%$ ainda não sabem o que fazer e $8 \%$ estão procurando emprego. 


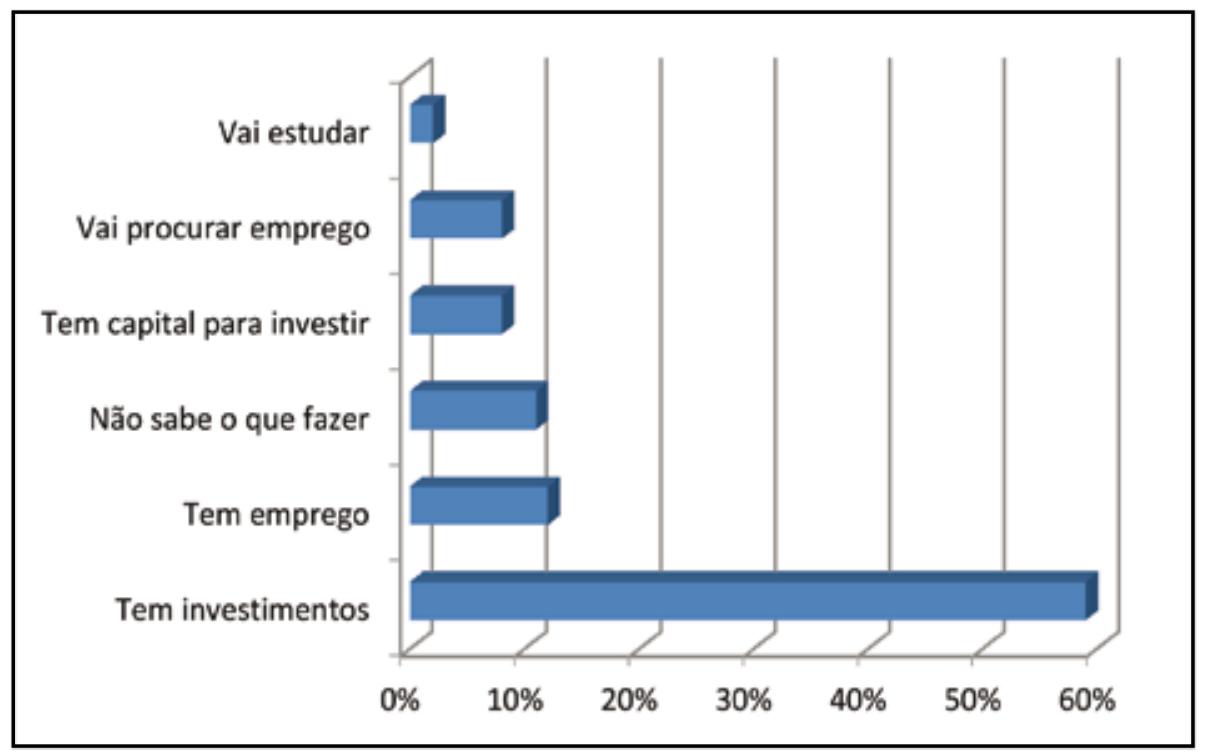

Fonte: Pesquisa de campo, $2011(n=237)$.

Estes dados nos levam a refletir sobre as condições de inserção desses retornados no mercado de trabalho em busca de renda para o seu sustento. Durante os anos de emigração eles não se qualificaram para as novas demandas do mercado. As experiências adquiridas no exterior não são comprovadas e assim não integram o currículo, o que os deixa em desvantagem em relação a outros concorrentes. Como empreendedores, não possuem conhecimento e nem experiência sobre administração, na maioria das vezes desconhecendo o mercado no qual desejam entrar ao abrirem seu próprio negócio.

Além disso, a adaptação ao trabalho, a incerteza e o estresse das condições de retorno comprometem o estado psíquico do emigrante, dificultando ainda mais sua inserção no mercado e limitando ainda mais as suas possibilidades de auferir renda.

Estudos realizados na Microrregião de Governador Valadares demonstram que os emigrantes que retornam com capital para investir nem sempre são bem sucedidos. Entre os entrevistados, $15 \%$ retornaram com capital e investiram na montagem de algum tipo de comércio. Entretanto, esses emigrantes não possuíam experiência como empreendedores e, durante os anos que estiveram fora do país, não ganharam nenhuma qualificação nessa área, pois trabalharam em atividades fora deste setor. Eles fazem seus investimentos sem conhecimento do mercado e em pouco tempo fecham suas empresas, como demonstrado no estudo de Siqueira (2009). 
Destaca-se que $20,7 \%$ do total de entrevistados pretendem emigrar novamente. Dentre eles, $82 \%$ ainda não sabem para qual país, $13,5 \%$ pretendem retornar para os Estados Unidos e 6\% pretendem emigrar para a Europa.

\title{
Economia brasileira
}

\begin{abstract}
A gente sempre vê falar que o Brasil está passando de liso pela crise, eu acho que deve estar sim [...] mas pra gente que ficou fora ainda está muito difícil [...], emprego não tem pra mim [...] quando aparece é um salário que dá tristeza [...] pra mim está difícil igual lá [...] só é melhor porque tem a família, os amigos e não tem que ficar com medo da $\mathrm{Mimi}^{8}$ [...] (Grupo focal Governador Valadares. Participante 5).
\end{abstract}

Mesmo avaliando a economia brasileira positivamente $-49 \%$ afirmam ter ótimas e, $30 \%$, boas expectativas em relação à economia nacional -, o relato acima demonstra a dificuldade de reintegração do retornado ao mercado de trabalho e as dificuldades desse em garantir o seu sustento. Deve ser destacado que nenhum entrevistado manifestou uma expectativa negativa em relação à economia brasileira, pois acreditam que irão superar as dificuldades e se inserir positivamente no mercado.

\begin{abstract}
Tem oito meses que retornei, trabalhava como motorista de caminhão, vivi 23 anos em Connecticut, sou cidadão, mas a coisa lá está pegando mesmo, resolvi vim para viver aqui, estou cansado e doente [...] preciso descansar [...]. Pra mim viver aqui é muito difícil, não consigo emprego [...] pedem documentos e experiência comprovada, mas os documentos que tenho não valem nada aqui [...]. Aqui tá bom para quem ficou, tem documentos, estudou [...]. Estou fazendo curso para conseguir trabalho [...]. Se fosse hoje eu não tinha ido, ia estudar, tem mais facilidades [...] (Grupo focal Governador Valadares, participante 6).
\end{abstract}

Este relato demonstra o drama daqueles que retornam em função da crise na economia americana depois de viver por vários anos nos Estados Unidos e sem possuir meios de sobrevivência ou renda no Brasil. Este participante viveu por 23 anos nos Estados Unidos e, mesmo possuindo documentação, sua permanência ficou insustentável e a opção foi retornar.

O drama vivido por este participante vai além da dificuldade de encontrar trabalho. Ele não fez nenhum investimento no Brasil, perdeu a casa que comprou nos Estados Unidos e, mesmo tendo retornado a passeio por várias vezes à cidade de origem, sente-se um estranho no local de origem, completamente deslocado. Ele se encontra em tratamento psiquiátrico, conforme declarou, e considera que fez uma péssima opção ao ter permanecido por longos anos fora do país. Sempre 
faz referência ao irmão mais novo que não emigrou, fez curso superior e hoje tem uma ótima posição no mercado de trabalho.

A inserção no mercado de trabalho depois de longos anos de ausência é difícil e exige desses emigrantes retornados paciência e a busca de qualificação. No gráfico 4 vê-se que um pequeno grupo entre os retornados (2\%) tem como projeto voltar a estudar para se qualificar.

Efeitos psicológicos do retorno sobre o emigrante em função da crise econômica nos Estados Unidos

Pode-se ressaltar que o retorno do indivíduo para seu município de origem sem conseguir seus objetivos, devido ao insucesso do projeto migratório, desencadeia vários fatores psicossociais, tais como: sentimentos de incapacidade, desilusão e vergonha.

O pior foi encarar todo mundo. Fiquei cinco anos e voltei pior do que fui [...] sem emprego, sem dinheiro e devendo à família [...]. É muito difícil [...] mesmo com apoio da família... é difícil demais .... (Grupo focal Capitão Andrade, participante 1).

O emigrante do relato acima tem 35 anos. Ele foi preso pela polícia de Imigração numa blitz de trânsito, ficou seis meses na cadeia e foi deportado. Vários membros da família emprestaram dinheiro para pagar as despesas com o advogado e a passagem de volta. Foi diagnosticado com síndrome do pânico e faz tratamento psicológico. Esse é um exemplo do que acontece e que apareceu com frequência nos grupos focais.

No gráfico 4 podemos observar que 11\% dos entrevistados afirmaram não saber o que iriam fazer para reconstruir seu projeto de melhoria da renda, depois do insucesso do projeto migratório. Essa incerteza e falta de perspectiva produz efeitos psicológicos negativos para o emigrante e sua família.

Neste sentido, concordamos com Sayad (2000), que afirma recair sobre os locais de origem o custo mais elevado da migração. Os países de onde sai a mão de obra barata para suprir o mercado de trabalho secundário dos países mais ricos recebem as remessas que movimentam o comércio e o setor de construção civil - como aconteceu e ainda acontece nos municípios da Microrregião de Governador Valadares. Entretanto, o custo social é muito alto, pois a maioria dos investimentos não é bem sucedida (SIQUEIRA, 2009) e, numa situação de crise, a política dos países de destino é a de deportar essa mão de obra que já não é mais necessária. $O$ retorno frustrado traz para casa cidadãos doentes e com sérias dificuldades de inserção no mercado de trabalho local.

\section{Considerações finais}

A emigração internacional é um fenômeno marcante na dinâmica social dos municípios da Microrregião de Governador Valadares. O boom do fluxo 
emigratório que ocorreu a partir da década de 1980 foi um dos fatores que possibilitou a dinamização da economia da região através das remessas enviadas pelos emigrantes. Nos municípios de origem, essas remessas foram aplicadas, principalmente, no setor da construção civil e no comércio, com a abertura de pequenos e médios empreendimentos.

$O$ retorno é parte integrante do projeto migratório. Ao longo dos quase 50 anos de fluxo migratório dessa região para os Estados Unidos, muitos retornaram, construíram suas casas coloridas e bem visíveis, deram nova arquitetura a bairros centrais e periféricos dos pequenos e médios municípios, bem como, em suas zonas rurais. Eles fizeram investimentos que remodelaram não só a arquitetura, mas também o cotidiano de seus locais de origem.

A emigração e o retorno de moradores fazem parte do cotidiano dos municípios da região. Contudo, a partir da crise econômica instalada nos Estados Unidos no ano de 2005 , o retorno começou a acontecer em proporção maior e em condições diferenciadas do que até então existia.

Ressalta-se que o número significativo de emigrantes retornados à Microrregião de Governador Valadares e o fracasso de grande parte, os têm levado a procurar emprego nos municípios de origem. Entretanto, é nítido o sentimento de frustração presente no retornado que não consegue emprego, pois após viver anos nos Estados Unidos, retorna na mesma condição de quando emigrou ou, em alguns casos, em condições piores.

Esta pesquisa demonstrou que o perfil do emigrante que retorna em função da crise não se diferencia de outros estudos, ou seja, são jovens, estão na faixa etária de 21 a 30 anos, estudaram de 8 a 10 anos e emigraram na década de 1990 e início da década de 2000.

O principal fator apontado como motivador da emigração foi a possibilidade de melhorar as condições econômicas. Antes de emigrar, a maioria dos entrevistados estava empregada, mas tinha uma renda que inviabilizava os projetos de consumo no curto prazo - ou seja, a aquisição da casa, carro e aumento da qualidade de vida. Nos Estados Unidos, a maioria trabalhava no mercado secundário, com uma jornada de mais de dez horas diárias, e ganhava entre 501 e 1000 dólares por semana. Apesar dessas condições, a maioria considera que tinha uma boa qualidade de vida naquele país.

Os emigrantes que retornaram após a crise econômica americana encontraram dificuldades para se inserir no mercado de trabalho. Contudo, apresentam uma visão positiva em relação à economia e à vida no Brasil. Eles reconhecem que a situação do Brasil diante da crise é melhor do que a dos Estados Unidos, mas consideram que as dificuldades para eles são grandes, pois os anos de ausência trouxeram desvantagens na hora de conseguir novamente a inserção no mercado de trabalho.

O principal motivo declarado pelos entrevistados para o retorno foi a saudade. Entretanto, é interessante ressaltar que a saudade faz parte da vida do emigrante. Ela só se torna motivo de retorno quando o "custo-benefício" da 
emigração deixa de ser positivo. O segundo fator apontado é a crise, uma vez que esta tornou desfavoráveis as condições de trabalho e renda. A insegurança e o medo da deportação são outros fatores que foram apontados pelos entrevistados para o retorno.

Os projetos citados para obter renda após o retorno ao Brasil foram distintos. Alguns já possuíam investimentos no Brasil. Outros retornaram com algum capital para investir. Outros, ainda, estavam à procura de emprego. Por fim, alguns emigrantes declaram não saber o que fazer. É visível a dificuldade do retorno em qualquer situação, independente do projeto. Entretanto, em função de um retorno não planejado e não desejado, essas dificuldades agravam-se mais. A ideia de fracasso e decepção está presente nos relatos desses personagens e muitos são acometidos por doenças psicológicas como depressão, síndrome do pânico e estresse.

O retorno não programado devido à crise traz de volta sujeitos que não conseguiram "fazer a América" e têm dificuldades de se inserir no mercado de trabalho de seus municípios de origem. Depois de anos de trabalho pesado, muitos retornam sem recursos e sem condições materiais e psicológicas para iniciar um novo projeto.

Esta é uma face do fenômeno da migração internacional vivenciada pelos municípios da Microrregião de Governador Valadares. O drama silencioso vivido pelos personagens dessa história não é visível, mas denuncia o lado perverso desse fenômeno e tem um elevado custo social para os locais de origem dos emigrantes.

\section{Notas}

1 - Artigo baseado na pesquisa "A Crise econômica no destino, o retorno dos emigrantes e seus impactos na Microrregião de Governador Valadares", financiada pela FAPEMIG - Fundação de Amparo à Pesquisa do estado de Minas Gerais, com apoio da UNIVALE - Universidade Vale do Rio Doce.

2 - Cidades da Microrregião: Alpercata, Campanário, Capitão Andrade, Coroaci, Divino das Laranjeiras, Engenheiro Caldas, Fernandes Tourinho, Frei Inocêncio, Galileia, Itambacuri, Itanhomi, Jampruca, Marilac, Matias Lobato, Nacip Haiddan, Nova Módica, Pescador, São Geraldo da Piedade, São Geraldo do Bachio, São José do Safira, São José do Divino, Sobrália, Tumiritinga, Virgolândia, Governador Valadares.

3 - Expressão usada pelos emigrantes, referindo-se a conseguir viver nos Estados Unidos.

4 - Com o intuito de preservar os informantes, todos os nomes que aparecem nos relatos são fictícios.

5 - Ter idade superior a 18 anos era um dos pré-requisitos para que o emigrante fosse incluído na amostra.

6 - Com a exigência do visto para o México, uma nova rota foi estabelecida, com os emigrantes entrando na Guatemala, de onde chegam até a fronteira do México por terra.

7 - Os agenciadores que financiam a emigração pela fronteira, as agências de turismo que organizam a viagem e toda a documentação para solicitação do visto americano são alguns exemplos.

8 - Como os emigrantes se referem à Polícia de Imigração. 


\section{Referências}

ASSIS, G. de O. Estar aqui, Estar lá... uma cartografia da vida em dois lugares. Dissertação (Mestrado em Antropologia Social) - Programa de Pós-Graduação em Antropologia Social, Universidade Federal de Santa Catarina, 1995.

ASSIS, G. de O. De Criciúma para o mundo: rearranjos familiares dos novos migrantes brasileiros. 1a. ed. Florianópolis: Editora Mulheres, 2011.

ASSIS, G. de O. Mulheres migrantes no passado e no presente: gênero, redes sociais e migração internacional. Revista Estudos feministas, Florianópolis, v. 15, no 3, p. 745-772, set./dez. 2007.

BRUSSEE, W. The second great depression. Starting 2007 eding 2020. EUA: Booklcker, 2005.

CARVALHO, F. C. de. Entendendo a recente crise financeira global. In: Dossiê da crise. Rio de Janeiro: Associação Brasileira Keynesiana, 2008. Disponível em: <http://www.ppge.ufrgs. br/akb>. Acesso em: 6 jul. 2012.

FAWCETT, J. T. Networks, Linkages and Migration Systems. Special Silver Anniversary Issue International Migration: an Assessment for the'90s. International Migration Review, New York, v. 23, no 3, p. 671-680, autumn 1989.

FUSCO, W. Redes sociais na Migração Internacional: o caso de Governador Valadares. Campinas: IFCH -UNICAMP, 1998.

HALL, S. Da diáspora. Identidades e mediações culturais. Belo Horizonte: UFMG, 2003.

HARBISON, S. F. Family Structure and Family Strategy in Migration Decision Making. In: DE JONG, G. F.; GARDNER R. W. Migration Decision Making: Multidisciplinary Approaches to Microlevel Studies in Developed and Developing Countries. New York: Pergamon Press, 1981, p.225-251.

MASSEY, D. S. et al. Return to Aztlan: the social process of international migration from western Mexico. Berkeley, Los Angeles, London: University of California Press, 1987.

MASSEY, D. S. Social Structure, Household Strategies, and the Cumulative Causation of Migration. Population Index, v. 56, no 1, p. 3-26, spring, 1990.

MASSEY, D. S. et al. Theories of International Migration: a Review and Appraisal. Population and Development Review, v. 19, n. 3, p. 431-466, sept. 1993.

MYRDAL, G. Rich lands and poor: the road to world prosperity. New York: Harper \& Brothers Publishers, 1957.

PIORE, M. Birds of passage: migrant labor and industrial societies. New York: Cabridge University Press, 1979.

SALES, T. Brasileiros longe de casa. São Paulo: Cortez, 1999.

SANTOS, M. A. et al. Migração: uma revisão sobre algumas das principais teorias. Belo Horizonte: UFMG/Cedeplar, 2010. (Texto para discussão № 398).

SAYAD, A. O retorno: elemento constitutivo da condição do imigrante. Travessia - Revista do Migrante, São Paulo, ano XIII, número especial, jan. 2000.

SILVA, J. O. et al. Impacto da Crise do Subprime no Endividamento das Maiores Empresas Brasileiras. Pensar Contábil, Rio de Janeiro, v. 12, n. 47, p. 16 - 25, jan./mar. 2010.

SIQUEIRA, S. Emigrants from Governador Valadares: Projects of Return and Investiment. In: JOUET-PASTRÉ, C. and BRAGA, L. J. (Editors). Becoming Brazuca. Brazilian Immigration to United States. Cambridge - Massachusetts: Harvard University Press, 2008, p. 175-194.

SIQUEIRA, S. Sonhos, sucesso e frustrações na emigração de retorno. Brasil/Estados Unidos. Belo Horizonte: Argvmentvm, 2009.

SIQUEIRA, S. Emigração, crise econômica e retorno à terra natal. Revista de Economia Política e História Econômica, v. 21, p. 5-25, jun. 2010.

STARK, O.; BLOOM, D. E. The New Economics of Labor Migration. The American Economic Review, v. 75, no 2, p. 173-178, may 1985. 
STARK, O.; TAYLOR, J. E. Relative deprivation and international migration. Demography, v. 26, no 1, p. 1-14, feb. 1989.

STARK, O.; TAYLOR, J. E. Migration Incentives, Migration Types: The Role of Relative Deprivation. The Economic Journal, v. 101, no 408, p. 1163-1178, sept. 1991.

TAYLOR, J. E. Differential migration, networks, information and risks. In: STARK, O. (ed.). Migration, human capital and development. Greenwich, Connecticut: JAI, v. 4, 1986, p. 147-171.

TORRES FILHO, E. T. Entendendo a crise do subprime. BNDES: Visão do desenvolvimento, $\mathrm{n}=44$, 2008. Disponível em: <http:// www.bndes.gov.br/conhecimento/visao/visao_44.pdf>. Acesso em: 7 jul. 2012.

\title{
RESUMO
}

O retorno faz parte do projeto migratório. Desde o início do movimento de emigração para os EUA, a partir da Microrregião de Governador Valadares nos anos de 1960, muitos têm retornado da aventura migratória, contudo a crise na economia americana resultou num retorno em uma intensidade maior que a normal num fluxo migratório. Este artigo busca compreender as condições desse retorno. A metodologia utilizada foi de cunho qualitativo e quantitativo. Foram aplicadas 237 entrevistas estruturadas em 25 cidades da microrregião em emigrantes retornados no período de 2006 a 2011. Os dados permitem considerar que os emigrantes eram jovens na faixa etária entre 21 e 30 anos, solteiros, e tinham como principal motivo de emigrar ganhar dinheiro, investir na sua cidade de origem e retornar numa situação econômica melhor. O principal motivo do retorno são as condições desfavoráveis para ganhar dinheiro e o acirramento da fiscalização quanto à documentação. A maioria não fez nenhum investimento no Brasil e retorna sem alcançar o projeto inicial. Buscam encontrar espaço no mercado de trabalho, contudo encontram dificuldades, devido aos anos de ausência, a defasagem de conhecimento e a baixa qualificação.

Palavras-chave: emigração; retorno; Governador Valadares (Brasil).

\begin{abstract}
Return is part of the migration project. Since the beginning, in the 1960s, of the emigration movement in the region around the city of Governador Valadares, Brazil, many people have returned from their migratory adventure. However, the recent crisis in American economy has made them return in a greater intensity. This article seeks to understand the conditions of this movement. Methodology was qualitative and quantitative. It was conducted 235 structured interviews among emigrants that returned from 2006 to 2011, in 25 cities of the referred region. The data allow to consider that the emigrants were mainly young people aged between 21 and 30 years old, unmarried, and had money as the main reason for emigration, planning to invest in their homeland and to come back in better economic situation. The main reasons for their return are the unfavorable condition to get money and the increase of immigration control on documentation. Most of the emigrants did not make any financial investment in Brazil and came back without reaching their initial goals. Now, they seek to find a space in the labor market, however, they find difficulties due to years of absence, knowledge gaps and low qualification.
\end{abstract}

Keywords: emigration; return; Governador Valadares (Brazil). 
